\title{
Using ideotypes to support selection and recommendation of varieties
}

\author{
Arnaud Gauffreteau* \\ UMR Agronomie, INRA, AgroParisTech, Université Paris-Saclay, 78850 Thiverval-Grignon, France
}

Received 11 May 2018 - Accepted 29 July 2018

\begin{abstract}
Climate change, synthetic input reduction and new cropping practices contribute to renew deeply and rapidly the cropping conditions and the required attributes of the varieties. To provide varieties adapted to those multiple cropping situations and objectives, stakeholders of selection, assessment and recommendation need new methods. Indeed, selecting a variety on a large number of objectives simultaneously may be complicated and inefficient. To improve the efficiency of the selection, Donald (1968) proposed an ideotype-based approach. It consists first in building a plant model by pointing out the mechanisms and plant traits to reach the goals and then only selecting varieties on those traits. To do so, a three-step method is presented: (i) defining the varietal specifications; (ii) designing and building an ideotype; and (iii) selecting varieties according to the ideotype and assessing their ability to meet the specifications. Tools available for helping the implementation of such a method are identified in different fields (computing, design, genetics...). This ideotype approach is presented as a valuable framework to support a collective design as it eases the interactions between stakeholders from different scientific and technical fields and the use of different forms of knowledge either scientific or empirical.
\end{abstract}

Keywords: ideotype / design / genotype x environment interaction / model

Résumé - Intérêts et limites du concept d'idéotype pour la sélection et le conseil variétal. Le changement climatique, la réduction des intrants de synthèse et la diversification des pratiques culturales contribuent au changement rapide et en profondeur des environnements de culture et appellent un renouvellement des profils variétaux. Pour fournir des variétés adaptées à ces objectifs et situations de cultures multiples, le sélectionneur, l'évaluateur ou le conseiller a besoin de méthodes nouvelles. En effet, la sélection de variétés sur une multiplicité d'objectifs peut s'avérer aussi compliquée qu'inefficace. Pour accroître l'efficacité de la sélection, Donald (1968) propose de baser cette sélection sur la notion d'idéotype. Il s'agit de construire en amont de la sélection un modèle de plante en identifiant l'ensemble des caractères de la plante qui lui permettraient d'atteindre les objectifs fixés, puis seulement de sélectionner les variétés sur la base de ces quelques caractères. Nous présentons, dans cet article, une méthode pour opérer cette sélection sur idéotype : (i) définir un cahier des charges; (ii) concevoir et construire un idéotype répondant au cahier des charges; puis (iii) sélectionner des variétés selon cet idéotype et évaluer leur capacité à répondre aux différents objectifs du cahier des charges. Des outils facilitant la mise en œuvre de la démarche sont identifiés dans le domaine de l'informatique, de la génétique ou encore des sciences de la conception. Cette démarche basée sur la définition d'un idéotype offre un cadre intéressant pour la conception collective en facilitant les échanges entre acteurs de champs disciplinaires variés et en permettant l'utilisation de différentes formes de connaissances (scientifiques ou empiriques).

Mots clés : idéotype / conception / interaction génotype $\mathrm{x}$ environnement / modèle

This paper aims at illustrating why the current changes in agriculture renew the potential interest of breeding plant

\footnotetext{
* Correspondence: arnaud.gauffreteau@inra.fr
}

according to an ideotype. After a presentation of the changes occurring the last 70 years in both cropping practices and breeding goals in France, we define the concept of ideotype and describe its potential assets. We finally propose and discuss a method to breed ideotypes defined collectively in a French 
group gathering both researchers and professionals in plant breeding, variety testing and recommendation.

\section{Changes in cropping conditions and breeding goals}

During the second half of the twentieth century, the cropping conditions have been controlled by an increasing use of synthetic fertilisers, regulators and pesticides resulting in a homogenisation of the environment towards an optimum for the plant growth. This control of the potential limiting factors resulted in an increase of sowing density and a simplification of the cropping system through shortening rotation and increasing field area. In coherence with this control of the cropping environments, breeders selected varietal types able to maximise yield and quality under non-limiting conditions and therefore over large cropping areas. Those trends in both cropping practices and plant breeding led to an unprecedented increase in agricultural productivity. As an example, the yield of wheat increased in France by $1.26 \mathrm{q} / \mathrm{ha} /$ year between 1960 and 1990, half of which being attributed to genetic progress (Brancourt-Hulmel et al., 2003).

This systematic and important use of synthetic inputs also impacted negatively the environment by increasing pollution of both the atmosphere and the groundwater and reducing biodiversity (MEA, 2005; Vitousek et al., 1997). From the nineties, the intensive agriculture was questioned and regulations on nitrogen and pesticides use were established to decrease this environmental impact. Based on new agronomic knowledge, progress was observed in the management of the inputs. First, the efficiency of the inputs were improved by the definition of new rules for application based on field observations (like the balance sheet method for nitrogen fertilization - Meynard et al., 1997) and sometimes by the building of monitoring tools (e.g. Ravier et al., 2018 for nitrogen fertilization). A step forward has consisted in designing new cropping systems decreasing simultaneously and consistently several inputs (seeds, growth regulators, $\mathrm{N}$ fertilisation, fungicides...) without impacting the profitability for farmers (Meynard, 1991). Whatever the leverage, this decrease in the use of synthetic pesticides and fertilizers led to an increase in the diversification of the cropping environment in terms of limiting factors. In order to decrease the dependency of new varieties to chemical inputs and adapting them to more diverse and stressed cropping environments, new breeding goals were progressively considered from the nineties beside yield and quality, mainly nitrogen use efficiency, lodging and pest resistance. Those new breeding goals provided multi-resistant varieties, that, when used in integrated cropping systems, showed comparable and sometimes better economic results than more intensive cropping systems as shown on soft winter wheat by Loyce et al. (2012). Beside the still dominant intensive agriculture, many alternative practices sometimes inspired by ecology concepts are proposed and experimented by researchers and pioneer's farmers like longer crop rotation integrating cash crops and multi-services cover crops, mixtures of cultivars and species (Barot et al., 2017; Hauggaard-Nielsen et al., 2001) or new landscape organisations and conservation agriculture. Among the alternative cropping systems, the organic agriculture has sharply increased over the past decades with a $135 \%$ growth of the worldwide organic agriculture area between 2001 and 2011 hiding important differences between countries (Paull, 2011). Those promising cropping practices and systems ask for selection on a broader range of species and on new breeding goals like the competiveness against weeds or the mixing ability of a variety (i.e. its ability to grow among other varieties or species) which are of particular interest in organic agriculture (Fontaine et al., 2009). Finally, the ongoing climate change towards higher temperatures and water deficit incites breeders:

- to revise their classical target population environments;

- to orientate their selection toward varietal characteristics like the resistance to abiotic stresses (e.g. Zheng et al., 2012).

This research on the subject is very active both in private and public sector through the funding of important French and international projects on various species (wheat, maize, pea, oilseed rape, sunflower, biomass crops...).

Dealing with an increasing number of breeding goals emerging from those changes in climate, cropping systems and post-harvest use is a difficult challenge for breeders. Some of those goals are known to be antagonistic. As examples, a negative genetic correlation has been shown between yield and protein content in wheat (Oury and Godin, 2007), the mechanisms responsible for the resistance to diseases have been shown to be sometimes costly for the plant and affect its yield (Brown, 2002) and increasing the competiveness against weeds would also lead to an increased competition between the crop individuals, an over-investment in the resource (light, nutrients...) capture function at the expense of fitness-related functions of the population such as reproduction (Anten and Vermeulen, 2016) and finally a reduction of the yield.

Those antagonisms between varietal traits are responsible for the genotype $\mathrm{x}$ environment $\mathrm{x}$ cropping systems interactions currently observed in the varietal trial networks and that are to grow with the expected decrease in chemical inputs, diversification of production techniques and climate change (Van Eeuwijk et al., 2016). In this context, the concept of varieties adapted to large cropping areas appears utopian and should be replaced by more locally adapted varieties presenting contrasted profiles. However, selecting and producing varieties adapted to various environments will not be sufficient for those varieties to be adopted by farmers. Indeed, a thorough characterisation of the varieties including information on traits not routinely measured today like the resistance to water and nitrogen stresses is required to adapt the varietal choice to each cropping situation. Varietal selection and recommendation are made even more difficult by the interannual variability. Therefore, the stability of the production is and will remain an important question for the farmer and the breeder. However, this stability will have to be considered not only at the scale of the variety as currently done by breeders in multi-environment trials, but better at the scale of several varieties. Indeed, more than one variety is generally cultivated each year by a farmer and this multi-varietal panel has been shown to be an important leverage to limit instability (Barkley et al., 2010). Therefore, the singularity of a variety and its complementarity to the currently available varieties should be 
also considered when defining the variety profile to select or recommend.

We illustrated in this first part that the climate change, the increasing social demand for a sustainable agriculture and the new regulations on the use of chemical inputs that lead to new cropping practices need to revise in depth the properties of the future varieties and the ideotypes that guide the selection. To meet this challenge, breeders, researchers and advisors need shared concepts and methods to design the future varieties and produce the information about their adaptation to local cropping conditions and outlets.

\section{Defining an ideotype: what and what for?}

Donald (1968) first defined an ideotype as a "biological model which is expected to perform or behave in a predictable manner within a defined environment". This plant model consists in a combination of physiological and morphological traits known to influence positively the performance of a plant in the target environment. Including the demand of the downstream chain and the genetic basis of the traits under consideration, Debaeke and Quilot-Turion (2014); defined an ideotype as "an optimal combination of morphological and physiological traits or of their underlying genetic basis that results in an efficient matching of the plant material to its environment, its cropping system and the demand of the consumer".

This concept of ideotype was initially proposed as an interesting tool to renew classical empirical breeding approaches mainly based on:

- defect elimination like disease sensitivity or physical imperfection;

- selection for yield without consideration of the why and wherefore of that greater yield.

Donald (1968) proposed the ideotype breeding as a third interesting way for selection. It consists in using existing knowledge mainly in ecophysiology to identify traits of interest in defined cropping conditions, combine those traits into an ideotype and select the varieties according to this ideotype. Even if scarce in the scientific literature, some ideotype breeding experiences have been successful. The most popular success of ideotype breeding is probably on rice. Peng et al. (2008) showed yields obtained by a selection on an ideotype 8 to $15 \%$ higher than those obtained by classical selection. In this case, the ideotype consisted in a plant with a moderate tillering capacity, heavy and dropping panicles and some morphological traits of the top three leaves and a position according to the panicle that optimise the sources-sinks relationships.

Initially developed on annual pure crops (Mock and Pearce, 1975; Rasmusson, 1987; Peng et al., 2008; Hanocq et al., 2009; Loison et al., 2017), the ideotype-based approach is generic and has also been experienced on perennial species like forest and fruit trees (Dickmann et al., 1994; Socias et al., 1998; Lauri and Costes, 2005; Cilas et al., 2006; Solis-Guillen et al., 2017) and more recently on heterogeneous crops like variety mixtures (Borg et al., 2015).

The ideotype breeding has potential to increase the efficiency of the selection. Indeed, Donald (1968) defended that the success of the classical selection for yield is partly based on good fortune that could be lowered by integrating in the selection process the mechanisms and related traits responsible for higher yield. This assumption apart, it is clear that yield (in grain or biomass) is not possible to estimate properly in the first years of selection because of the limited quantity of available material and the growing conditions that can be very different from those encountered in a crop field. Therefore, by identifying traits responsible for high yielding in real cropping conditions that can be measured precisely and early in the selection process, the breeder is able to select earlier for yield and therefore be more efficient on improving it. This breeding approach is all the more useful in the current selection context with an increasing number of breeding goals that can be poorly related to each other and sometimes be antagonistic (see part 1). Identifying the traits and mechanisms impacting the various breeding goals and integrating them in a single model make it possible to disentangle the existing correlation (negative or positive) between those goals and to identify combinations of traits, sometimes poorly related to each other, that provide an acceptable trade-off between the targeted goals. Cruz (2006) proposed an index for selection based on the definition of an ideotype called genotypeideotype distance index that has been shown interesting in multi-criteria selection (Teixeira et al., 2017).

Another asset of this ideotyping approach lies in the formalization of traits and mechanisms into plant models that can be reused for different species and contexts of production. It is clear that the wheat ideotype and the underlying physiological mechanisms and morphological traits proposed by Donald (1968) have inspired those proposed for other cereals like maize (Mock and Pearce, 1975) or rice (Peng et al., 2008). Schmidt and Gaudin (2017) illustrated the possibility to design generic ideotypes. They developed and compared root ideotypes for irrigated and rainfed systems that may be of interest for several annual crops. Finally, the ideotyping approach offers a framework to ease the interspecific sharing of new concepts and knowledge and therefore the possibility of accelerating genetic progress in a more collective way.

Breeding and recommending varieties have in common that both are looking for varieties able to reach some agronomic goals in one or a population of target environments. Therefore, the ideotyping approach above-described as a tool of interest in a breeding context is also useful for varietal recommendation. Indeed, the identification of traits implied in the adaptation of the plant to specific cropping conditions would help at improving the characterisation of the varieties (like the resistance to abiotic stresses), at disentangling the GxE interaction observed in variety trials, at defining the ideotype best adapted to locally cropping conditions and finally at identifying the ideotype-like variety among the offered possibilities.

Supported by the development of plant and crop models and a rapid improvement of the computing power, researchers have identified traits of potential interest in particular cropping conditions. However, those academic studies have not yet convinced the breeders and advisors who are still reluctant in choosing their genotypes according to a predetermined model of plant. A reason for this lies probably in the conceptual aspect of the ideotype approaches. It lacks a practical method for the 


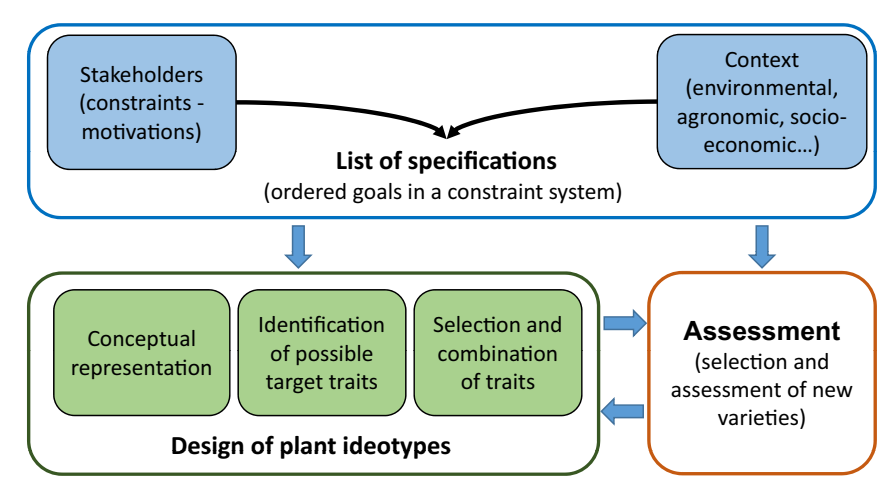

Fig. 1. The main steps of an ideotyping process.

design of ideotypes that would detail the steps to implement, the useful tools and the stakeholders to involve at each step.

\section{A method to design ideotypes}

The method described below results from a collective discussion developed during a research school and a seminar ${ }^{1}$ in France on ideotype topic. It has been precisely described in Debaeke and Quilot-Turion (2014) and in Debaeke et al. (2014). It consists in (i) defining the specifications of the varieties; (ii) designing and building the ideotypes; and (iii) assessing their ability to meet the specifications (Fig. 1).

\subsection{The definition of the varietal specifications}

Before any breeding process based or not on an ideotype, one must define and order the expected attributes of the varieties namely the breeding goals. Defining those goals is not a task for the only breeder. The key stakeholders carrying expectations for the future varieties should be involved and their constraints and motivations should be described and discussed. Indeed, few stakeholders can impede severely the development of an innovation. For instance, if mixing varieties of wheat or barley is an highly efficient leverage for regulating some aerial diseases (Finckh et al., 2000) and has therefore an obvious interest for the producers, their adoption remained limited partly because of the reluctance of the grain collectors and the processors (like industrial bakery, brewery...) to deal with the heterogeneity of the harvested grain. As illustrated by Vanloqueren and Baret (2008) on multi-resistant wheat cultivars, the organisation between stakeholders in a foodchain can also create a lock-in situation where the development of forthcoming innovations is impossible without a shared interest. Therefore, this collective definition of the specifications of the crop ideotype is necessary before selection as it will improve the chances of success of the future varieties and limit the risk to invest in the wrong ideotype. The constraints of the stakeholders must be thoroughly discussed and alternative leverage (technical, organisational...) to ease those constraints must be considered in order that the specifications remain reachable for one or several varieties.

\footnotetext{
${ }^{1}$ Seminar "Idéotypes variétaux", GIS GC-HP2E and GIS Fruit, 7-8 february 2013, Paris.
}

Beyond the stakeholders' requirements, the specifications must be based on the definition of an overall context of production (environmental, agronomical, ecological, social, political...). A crucial step lies in delineating a target population of environments (TPE), that is, a set of environments sharing similar environmental stress patterns in which the selected varieties are expected to grow. Those TPE should consider the expected change to come in climate and cropping practices as described in part 1. Changes in cropping conditions may lead to necessary adaptation of the current varieties and underlying ideotypes as shown by several authors like Schmidt and Gaudin (2017) who defined very different root ideotypes for irrigated and rainfed cropping systems. That's why the ideotypes proposed in the literature are generally associated to a precise description of the cropping conditions. For instance, the wheat ideotype proposed by Donald (1968) (see Box 1) has been shaped to perform well in pure stands and under intensive cropping practices (high sowing density and nitrogen supply, chemical weed control...) and would not be adapted to low input systems. Indeed, being a weak competitor with low tillering capacity, small stems and erected leaves reduces significantly the ability for weed suppression capacity and for supporting variation in resources supply or in emergence rate. The definition of the future TPE will benefit from the recent advances in defining and measuring the environmental stresses with crop models and then in clustering cropping environments according to those stresses (Chenu et al., 2011 and 2013). The current interannual variability of cropping conditions and its expected increase due to both an increase of the weather variation and a decrease of the inputs is a key point in the way of defining the TPE. Indeed, a geographical definition of the TPE as done by some authors (e.g. Braun et al., 1996; Hernandez-Segundo et al., 2009) wouldn't be relevant since one variety could hardly be adapted to one location whatever the year. A better way is to define TPE on the location $\mathrm{x}$ year situations accepting that one location may experience different stress profiles and may belong to several TPE according to the year (e.g. Zhang et al., 2006 for disease in France; Chenu et al., 2013 for drought in Australia). This would lead to more homogeneous TPE and therefore to a reduction of the number of breeding goals. Furthermore, one farm could be described by the main TPE they belong to, giving the opportunity to improve the stability of the production by recommending a set of complementary varieties adapted to those TPE and the underlying environmental stress patterns.

\subsection{The design of new ideotypes}

Breeding is classically a step-by-step process, improving the existing varieties by crossing with parents bearing interesting attributes. This breeding process may not be adapted to rapid changes in cropping conditions and to a diversification of the consumer demand and the cropping practices that need to renew the varietal offer with profiles sometimes very different from the one under selection. This requirement is already observed in some French organic cropping systems with an important use of foreign cultivars and the development of local participatory breeding programs. The ideotype breeding gives the opportunity of speeding up the selection of breakthrough varieties by first defining a plant 


\section{Box 1. Short illustration from the wheat ideotype proposed by Donald (1968) (The breeding of crop ideotypes, Euphytica 17: 385-403).}

\section{Specifications:}

Donald (1968) aims at defining an ideotype capable of high grain yield when grown as a crop community and under high sowing density. Cropping environments are those of intensive agriculture favorably endowed for water and nutrient supply and well controlled for weeds and pests.

Main strategies:

- Limiting the competition between wheat plants: Str.1

- Minimizing the demand on resources per unit of dry matter produced by

- Maximizing the use of resources, mainly the light: Str.2-a

- Minimizing the waste of resources (i.e. the use of resources that do not lead to an increase of grain biomass): Str.2-b

- Ensuring that the ear is not a limiting sink for the photosynthates produced by plants: Str.3

\section{Traits of interest:}

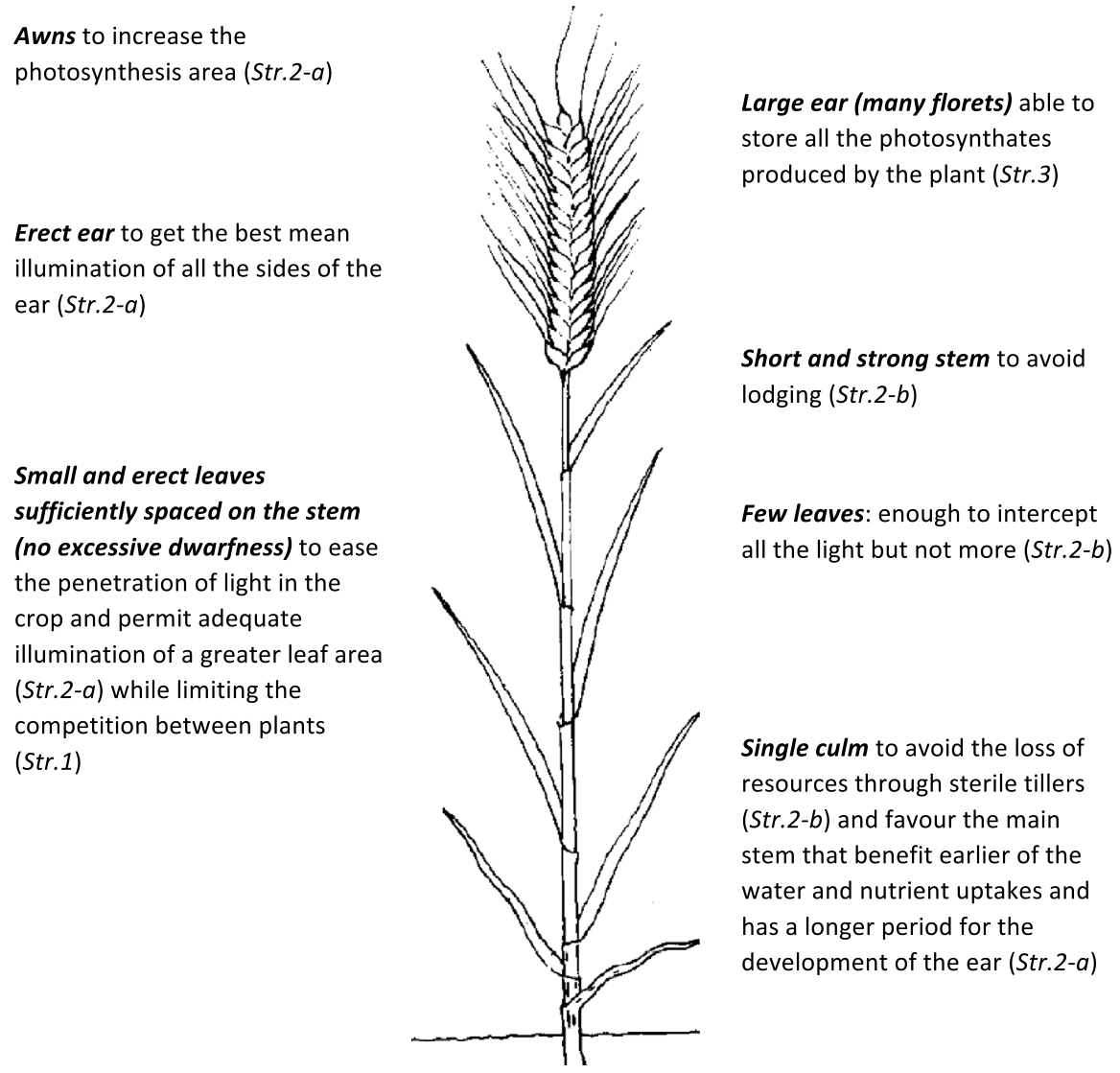

model that can differ a lot from current variety profiles. The design of new ideotypes is a creative process which first consists in defining a conceptual representation, that is, a set of strategies to meet the specifications previously described. As an example, to increase the wheat productivity in a dense population, Donald (1968) conceptual representation results in a plant that is a weak competitor making a minimum demand on resources per unit of dry matter produced. The conceptual representation may be based on strategies whose feasibility hasn't been properly assessed. Wheat varieties able to fix the nitrogen as legumes or to inhibit the nitrification are for instance breakthrough strategies under study to improve the resistance of a wheat to nitrogen stress. This creative step of the ideotype design may involve stakeholders of various origins (scientists in genetics, agronomy, physiology, pathology and professionals like breeders, examination offices, advisors or farmers) that share and discuss different forms of knowledge (scientific, expert, observations, intuitions...). Which methods to support such a design process is a key question. Agronomists working on the design of new agricultural 
systems have mobilised, proposed and compared several participatory approaches (Prost et al., 2018; Berthet et al., 2015) that could be adapted to the case of ideotypes. Those participatory approaches are also good ways to identify gaps of knowledge that could justify new researches.

Once the conceptual representation is established, the next step consists in pointing out the traits to implement the proposed strategies (growth rate, phenology, plant height and architecture, leaf shape and habit...). Those possible target traits are generally assessed by geneticists in terms of available genotypic diversity and the constraints it imposes (heritability, correlations between traits due either to linkage disequilibrium or to pleiotropy). However, they are also sometimes reachable by cropping practices (growth regulator to impact the plant height, sowing date to impact the plant phenology, pruning to impact the tree architecture...) that can be assessed by their feasibility, efficiency and cost. Those two leverages (genetic and technical) must be considered so that the breeding only focuses on the traits that are accessible with the existing genetic material, heritable and not efficiently reachable by cropping practices. For instance, the strategies of conferring to wheat the ability to fix atmospheric nitrogen or to inhibit the nitrification in the soil are long term and expensive strategies for breeding. They should be compared to existing technical ways such as enriching the soil in nitrogen by introducing more legumes in the rotation, decreasing the nitrogen demand by growing mixtures of wheat and legumes or avoiding the nitrogen leaching by sowing catch crops. An ideotype being a combination of target traits to reach the main breeding goals, one must consider carefully the genetic correlation between the possible target traits. In literature, the identification of the possible target traits and their combination into ideotypes are supported by both field trials and crop models. Trials generally consist in testing contrasted genotypes well described for their phenotype in target environments and result in identifying traits of interest to reach a particular objective (e.g. Polania et al., 2017 for the root traits improving the drought tolerance in bean or Hammami et al., 2017 for the traits involved in the resistance to salinity in barley). Those "real life" approaches based on existing varieties and environment are useful to fulfil knowledge gaps and confirm some hypothesis about possible traits of interest. However, they generally require expensive phenotypic characterisation and are limited by the number of environmental conditions under study. That's probably why their number remains quite limited in the literature about ideotypes. More frequent are the computer modelling approaches particularly in the recent literature (e.g. Haverkort and Kooman, 1997; Asseng et al., 2002; Voisin et al., 2007; Qi et al., 2010; Casadebaig and Debaeke, 2011; Suriharn et al., 2011; Kadrani et al., 2012 ; Quilot-Turion et al., 2012 ; Semenov and Stratonovitch, 2013). Computer models are efficient tools to gather and formalize different types of knowledge (expert or scientific) in various fields (ecophysiology, genetic, pathology, agronomy...). Combined with powerful optimisation algorithms, those models can help at pointing out the traits and combination of traits for reaching some target goals and therefore can be very useful for defining ideotypes or identifying varieties adapted to particular cropping conditions. Martre et al. (2015), Rotter et al. (2015) and Jeuffroy et al. (2014) gave more details on how models can support the design of ideotypes and their recommendation. Those computer models are very interesting to explore breakthrough combination of traits or cropping conditions and therefore predict the behaviour of totally new varieties in future cropping environments. However, one must keep in mind that those models have important limitations. First, they are partial. For instance, very few models take into account the biotic stresses (diseases, insects or weeds). Secondly, the models are calibrated on a limited number of existing varieties and cropping conditions. Therefore, to test new ideotypes in new cropping conditions, the models are generally run out of their validity domain and the results obtained should be considered very cautiously. As those results can also be very dependent on the model considered, using several models can improve the robustness of the results (Tao et al., 2017). For those model-based approaches to be useful in breeding or recommending varieties, the key parameters of the models (those having an impact on the target goals) must be measurable so that the varieties can be selected on it and the genetic diversity as well as the between traits correlations must be credible even if different of the currently observed. Finally, if simulations are less expensive than trials, the development of the right models is generally the limiting step of a computing-model based approach. Modelling platforms like RECORD (Bergez et al., 2013) or ISIde (Paleari et al., 2016) giving access to models and computing tools to combine models or design and implement simulation batches is of utmost importance for an "in silico" ideotyping to be implemented by noncomputer scientists.

\subsection{The assessment of ideotypes}

Once the ideotype defined, its assessment will be based on varieties selected according to this ideotype. Therefore, the challenge is to select those varieties in an efficient way. This will be all the easier that the traits for selection are easily and precisely measurable, that some genetic markers are available and that one has access to rich and well characterized genetic resources. The development of high throughput phenotyping tools is therefore very useful to characterize large panels of genotypes on the target traits and identify QTL related to those traits in defined cropping conditions.

The selected varieties must be assessed in cropping conditions representative of the target population of environments and according to the specifications previously listed. This assessment is classically implemented in a multienvironment trial. It is based on a precise characterization of the environmental conditions that can be partially controlled experimentally (e.g. for water, temperature, $\mathrm{CO}_{2} \ldots$ ) and an analysis of the genotype $\mathrm{x}$ environment interactions aiming at delineating the optimal cropping conditions for the varieties under study. If those GxE analysis are classically applied on individual variables like yield, they are much more complicated and scarce in literature when applied simultaneously on several variables of interest (e.g. yield, resistance to diseases, quality variables...). This multi-criteria analysis helps identify some critical defaults of the varieties that could lead to modifications of the underlying ideotype. 


\section{Why not selecting an ideotype?}

Whatever the potential quality of an ideotype-based approach, some relevant criticisms have to be considered.

First, designing an ideotype requires to find and organise knowledge in various scientific fields. If some major species $(e . g$. wheat, maize, potatoes, fruit trees...) are well documented, some minor ones have been much less studied (orphan crops). This lack of knowledge might seem to be an obstacle to define an ideotype. However, different leverages can be activated to fulfil this knowledge gap. First, interesting knowledge can be found in related species and extrapolated. Secondly, even if not scientific, other sources of knowledge (called expert, traditional, empirical or lay) can be shared and organized in expert based models that can support an ideotype process. Combining different sources of knowledge is common in agronomy to produce innovative local solutions and has been shown to catalyse both design processes and knowledge production (Prost et al., 2016). Collecting expert knowledge, making it explicit and combining it in a shared plant model could support both the selection of new varieties adapted to local cropping conditions and the production of a shared collective knowledge base that will help the next ideotyping dynamics.

Secondly, this approach needs skills in various scientific and technical domains. It is competed by genetic methods, like genomic selection, using genetic information to predict directly the value of a genotype for the main breeding goals. Affordable genetic data and turnkey statistic models made those black-box models very attractive. However, their ability to predict Genotype x Environment interactions remains poor (Heslot et al., 2014; Ly et al., 2018). Combining ideotype design and genetic models by first identifying traits related to breeding goals and less sensitive to environment conditions and secondly applying genomic models on those traits could be more efficient.

Thirdly, if ideotype based approach can improve breeding efficiency by first identifying traits to be selected, we must also assume that non-optimal ideotypes and traits would lead efficiently to deficient varieties. And the risk of designing a non-optimal plant model increases with the number of breeding goals to consider. Indeed, if ideally an ideotype based approach should consider all the breeding goals simultaneously, in practice, they are often considered successively because knowledge and tools for designing ideotypes are generally specialized and partial. For instance, crop models that are used to design ideotypes in various cropping conditions scarcely consider disease although this stress is of utmost importance in crop growth. In those conditions, it is expected that the first versions of an ideotype turn out to be not optimal for some target goals not properly considered in the design step. However, the ideotype approach as presented in Figure 1 is not straightforward, ideotypes are defined according to several design - assessment loops. During this process, enough genetic diversity must be maintained in the material under selection to support modifications of the ideotype and small changes in the breeding target traits.

\section{Conclusion}

Finally, ideotype breeding differs from classical practices in selection only by an additional design step aiming at pointing out the mechanisms and the plant traits underlying the target breeding goals. Therefore, there is no antagonism between ideotype breeding and the current breeding ways. Both could benefit from the same genetic tools like genomic models that could be applied either directly on breeding goals or on traits related to those goals. The increasing number of expected attributes for the varieties and the current diversification of the cropping conditions lead to an increase of breeding goals that are impossible to breed for simultaneously and efficiently. In those particular conditions, first targeting a limited number of measurable traits involved in the achievement of those goals could become necessary to ease the work of the breeder and improve the efficiency of selection.

This ideotype-based approach is also an interesting framework to support a collective design involving stakeholders from different science and technical fields that are not used to work together. By specifying the strategies and mechanisms and the underlying traits, the design of ideotypes is a valuable way to pool and share different forms of knowledge. It also eases the extrapolation of some concept from one species to another as shown by the model proposed by Donald (1968) for wheat that has clearly inspired the design of ideotypes in several other species. It is therefore a valuable approach for some minor species whose knowledge is generally scarce. The design - assessment loops may also give birth to innovative knowledge or at least innovative path for further research.

\section{References}

Anten NP, Vermeulen PJ. 2016. Tragedies and crops: understanding natural selection to improve cropping systems. Trends Ecol Evol 31: 429-439.

Asseng S, Turner NC, Ray JD, Keating BA. 2002. A simulation analysis that predicts the influence of physiological traits on the potential yield of wheat. Eur J Agron 17: 123-141.

Barkley A, Hawana Peterson H, Shroyer J. 2010. Wheat variety selection to maximize returns and minimize risk: an application of portfolio theory. J Agric Appl Econ 42(1): 39-55.

Barot S, Allard V, Cantarel A, Enjalbert J, Gauffreteau A, Goldringer I, Lata JC, Le Roux X, Niboyet A, Porcher E. 2017. Designing mixtures of varieties for multifunctional agriculture with the help of ecology. A review. Agron Sustain Dev 37(2): 13.

Bergez JE, Chabrier P, Gary C, Jeuffroy MH, Makowski D, Quesnel G, Ramat E, Raynal H, Rousse N, Wallach D, Debaeke D, Durand P, Duru M, Dury J, Faverdin P, Gascuel-Odoux C, Garcia F. 2013. An open platform to build evaluate and simulate integrated models of farming and agro-ecosystems. Environ Model Software 39: 39-49.

Berthet E, Barnaud C, Girard N, Labatut J, Martin G. 2015. How to foster agroecological innovations? A comparison of participatory design methods. J Environ Plan Manage 59(2): 280-301.

Borg J, Enjalbert J, Gauffreteau A. 2015. Concevoir des associations variétales par l'idéotypage participatif. Colloque CLIMAGIE : adaptation des prairies au changement climatique - Amélioration génétique et intensification écologique 16-17/11/2015, Poitiers France.

Brancourt-Hulmel M, Doussinault G, Lecomte C, Bérard P, Le Buanec B, Trottet M. 2003. Genetic improvement of agronomic traits of winter wheat cultivars released in France from 1946 to 1992. Crop Sci 43: 37-45. 
Braun HJ, Rajaram S, van Ginkel M. 1996 CIMMYT's approach to breeding for wide adaptation. Euphytica 92: 175-183.

Brown JKM. 2002. Yield penalties of disease resistance in crops. Plant Biol 5: 339-344.

Casadebaig P, Debaeke P. 2011. Using a crop model to assess genotype-environment interactions in multi-environment trials. In Halford N, Semenov M, eds. System approaches to crop improvement. Aspects Appl Biol 107: 19-25.

Chenu K, Cooper M, Hammer GL, Mathews KL, Dreccer MF, Chapman SC. 2011. Environment characterization as an aid to wheat improvement: interpreting genotype-environment interactions by modelling water-deficit patterns in North-Eastern Australia. J Exp Bot 62: 1743-1755.

Chenu K, Deihimfard R, Chapman SC. 2013. Large-scale characterization of drought pattern: a continent-wide modelling approach applied to the Australian wheatbelt - spatial and temporal trends. New Phytol 198: 801-820.

Cilas C, Bar-Hen A, Montagnon C, Godin C. 2006. Definition of architectural ideotypes for good yield capacity in Coffea canephora. Ann Bot 97: 405-411.

Cruz CD. Programa GENES. Biometria UFV Ed. Viçosa, 2006.

Debaeke P, Quilot-Turion B, eds. Conception d'idéotypes de plantes pour une agriculture durable. Collection École-chercheurs INRA FormaSciences FPN INRA 2014, 252 p.

Debaeke P, Gauffreteau A, Durel CE, Jeuffroy MH. 2014. Conception d'idéotypes variétaux en réponse aux nouveaux contextes agricoles et environnementaux. $A E \& S 4$ (2): 9.

Dickmann DI, Gold MA, Flore JA. 1994. The ideotype concept and the genetic improvement of tree crops. Plant Breed Rev 12: 163-193.

Donald CM. 1968. The breeding of crop ideotype. Euphytica 17: 385403.

Finckh MR, Gacek ES, Goyeau H, Lannou C, Merz U, Mundt CC, Munk L, Nadziak J, Newton AC, de Vallavieille-Pope C, Wolfe MS. 2000. Cereal variety and species mixtures in practice with emphasis on disease resistance. Agronomie 20: 813-837.

Fontaine L, Rolland B, Bernicot MH, Poiret L. 2009. Des variétés rustiques concurrentes des adventices pour l'agriculture durable en particulier l'agriculture biologique. Innovations Agron 4: $115-124$

Hammami Z, Gauffreteau A, Belhaj Fraj M, Sahli A, Jeuffroy MH, Rezgui S, Bergaoui K, McDonnell R, Trifa Y. 2017. Yield reduction in improved barley (Hordeumvulgare L) varieties and landraces under salinity using selected tolerance traits. Field Crop Res 211: 10-18.

Hanocq E, Jeuffroy MH, Lejeune-Hénaut I, Munier-Jolain N. 2009. Construire des idéotypes pour des systèmes de culture variés en pois d'hiver. Innovations Agron 7: 14-28.

Hauggaard-Nielsen H, Ambus P, Jensen ES. 2001. Interspecific competition $\mathrm{N}$ use and interference with weeds in pea-barley intercropping. Field Crops Res 70: 101-109.

Haverkort AJ, Kooman PL. 1997. The use of systems analysis and modelling of growth and development in potato ideotyping under conditions affecting yields. Euphytica 94: 191-200.

Hernandez-Segundo E, Capettini F, Trethowan R, van Ginkel M, Mejia A, Carballo A, Crossa J, Vargas M, Balbuena-Melgarejo A. 2009. mega-environment identification for Barley based on twenty-seven years of global grain yield data. Crop Sci 49: 1705.

Heslot N, Akdemir D, Sorrells ME, Jannink JL. 2014. Integrating environmental covariates and crop modeling into the genomic selection framework to predict genotype by environment interactions. Theor Appl Genet 127: 463-480.
Jeuffroy MH, Casadebaig P, Debaeke P, Loyce C, Meynard JM. 2014. Agronomic model uses to predict cultivar performance in various environments and cropping systems: a review. Agron Sustain Dev 34: 121-137.

Kadrani A, Sidi MMO, Quilot-Turion B, Génard M, Lescourret F. 2012. Particle swarm optimization to design ideotypes for sustainable fruit production systems. Int J Swarm Intelligence Res 3: 1-19.

Lauri PE, Costes E. 2005. Progress in whole-tree architectural studies for apple cultivar characterization at INRA France-Contribution to the ideotype approach. Acta Hort 663: 357-362.

Loison R, Audebert A, Debaeke P, Hoogenboom G, Leroux L, Oumarou P, Gerardeaux E. 2017. Designing cotton ideotypes for the future: reducing risk of crop failure for low input rainfed conditions in Northern Cameroon. Eur J Agron 90: 162-173.

Loyce C, Meynard JM, Bouchard C, Rolland B, Lonnet P, Bataillon P, Bernicot MH, Bonnefoy M, Charrier X, Debote B, Demarquet T, Duperrier B, Félix I, Heddadj D, Leblanc O, Leleu M, Mangin M, Méausoone M, Doussinault G. 2012. Growing winter wheat cultivars under different management intensities in France. A multicriteria assessment based on economic energetic and environmental indicators. Field Crops Res 125(1): 167-178.

Ly D, Huet S, Gauffreteau A, Rincent A, Touzy G, Mini A, Jannink JL, Cormier F, Paux E, Lafarge S, Le Gouis J, Charmet G. 2018. Whole-genome prediction of reaction norms to environmental stress in bread wheat (Triticum aestivum L) by genomic random regression. Field Crop Res 216: 32-41.

Martre P, Quilot-Turion B, Luquet D, Ould-Sidi M, Chenu K, Debaeke P. Model assisted phenotyping and ideotype design. In: Calderini D, Sadras VO, eds. Crop physiology applications for genetic improvement and agronomy. 2nd Ed. Academic Press, 2015, pp. 349-373.

MEA. Ecosystems and human well-being: synthesis. Washington (DC) : C Island Press, 2005.

Meynard JM. Pesticides et itinéraires techniques. In: Bye P, Descoins C, Deshayes A, eds. Phytosanitaires protection des plantes biopesticides. Paris : INRA, 1991, pp. 85-100.

Meynard JM, Justes E, Machet JM, Recous S. Fertilisation azotée des cultures annuelles de plein champs. In: INRA, ed. Maîtrise de l'azote dans les agrosystèmes. Reims : Les colloques, 1997, pp. 183-200.

Mock JJ, Pearce RB. 1975. An ideotype of maize. Euphytica 24: 613-623.

Oury FX, Godin C. 2007. Yield and protein concentration in bread wheat: how to use the negative relationship between the two characters to identify favourable genotypes. Euphytica $157(1-2)$ : 45-57.

Paleari L, Bregaglio S, Cappelli G, Movedi E, Confalonieri R. 2016. ISIde: a rice modelling platform for in silico ideotyping. Comput Electron Agricult 128: 46-49.

Paull J. 2011. The uptake of organic agriculture: a decade of worldwide development. J Soc Develop Sci 2(3): 111-120.

Peng S, Khush GS, Virk P, Tang Q, Zou Y. 2008. Progress in ideotype breeding to increase rice yield potential. Field Crop Res 108: 32-38.

Polania J, Poschenrieder C, Rao I, Beebe S. 2017. Root traits and their potential links to plant ideotypes to improve drought resistance in common bean. Theoretical Exp Plant Physiol 29(3): 143-154.

Prost L, Berthet E, Cerf M, Jeuffroy MH, Labatut J, Meynard JM. 2016. Innovative design for agriculture in the move towards sustainability: scientific challenges. Res Eng Design 28(1): 119-129. 
Prost L, Reau R, Paravano L, Cerf M, Jeuffroy MH. 2018. Designing agricultural systems from invention to implementation: the contribution of agronomy lessons from a case study. Agricult Syst 164: 122-132.

Qi R, Ma Y, Hu B, de Reffye P, Cournede PH. 2010. Optimization of source-sink dynamics in plant growth for ideotype breeding: a case study on maize. Comput Electron Agr 71: 96-105.

Quilot-Turion B, Ould-Sidi MM, Kadrani A, Hilgert N, Genard M, Lescourret F. 2012. Optimization of parameters of the 'Virtual Fruit' model to design peach genotype for sustainable production systems. Eur J Agron 42: 34-48.

Rasmusson DC. 1987. An evaluation of ideotype breeding. Crop Sci 27: 1140-1146.

Ravier C, Jeuffroy MH, Gate P, Cohan JP, Meynard JM. 2018. Combining user involvement with innovative design to develop a radical new method for managing $\mathrm{N}$ fertilization. Nutr $\mathrm{Cycl}$ Agroecosyst 110: 117-134.

Rotter R, Tao F, Hohn J, Palosuo T. 2015. Use of crop simulation modelling to aid ideotype design of future cereal cultivars. $J$ Exp Botany 66(12): 3463-3476.

Schmidt J, Gaudin A. 2017. Toward an integrated root ideotype for irrigated systems. Trends Plant Sci 22(5): 433-443.

Semenov MA, Stratonovitch P. 2013. Designing high-yielding wheat ideotypes for a changing climate. Food Energy Security 2: 185-196.

Socias R, Felipe AJ, Gómez Aparisi J, Dicenta JEF. 1998. The ideotype concept in almond. Acta Hort 470: 51-56.

Solis-Guillen I, Chaires-Pacheco M, Juarez-Gomez J, O'ConnorSanchez A, Pena-Ramirez Y. 2017. Development of an Ideotypebased selection tool for native tropical tree breeding by smallholder planters in Mexico's Maya Forest. Small-Scale Forestry 16(4): 521-534.
Suriharn B, Patanothai A, Boote KJ, Hoogenboom G. 2011. Designing a peanut ideotype for a target environment using the CSM-CROPGRO-Peanut Model. Crop Sci 51: 1887-1902.

Tao F, Rotter R, Palosuo T, Diaz-Ambrona C, Minguez I, Semenov M, Kersebaum K, Nendel C, Cammarano D, Hoffmann H, Ewert F, Dambreville A, Martre P, Rodriguez L, Ruiz-Ramos M, Gaiser T, Hohn J, Salo T, Ferrise R, Bindi M, Schulman A. 2017. Designing future barley ideotypes using a crop model ensemble. Eur J Agron 82: 144-162.

Teixeira FG, Hamawaki OT, Nogueira APO, Hamawaki RL, Jorge GL, Hamawaki CL, Machado BQV, Santana AJO. 2017. Genetic parameters and selection of soybean lines based on selection indexes. Genet Mol Res 16(3).

Van Eeuwijk F, Bustos-Korts D, Malosetti M. 2016. What should students in plant breeding know about the statistical aspects of genotype $\times$ environment interactions? Crop Sci 56(5): 2119 .

Vanloqueren G, Baret P. 2008 Why are ecological low-input multiresistant wheat cultivars slow to develop commercially? A Belgian agricultural 'lock-in' case study. Ecol Econ 66(2-3): 436-446.

Vitousek PM, Mooney HA, Lubchenco J, Melillo JM. 1997. Human domination of Earth's ecosystems. Science 277(5325): 494-499.

Voisin AS, Bourion V, Duc G, Salon C. 2007. Using an ecophysiological analysis to dissect genetic variability and to propose an ideotype for nitrogen nutrition in pea. Ann Bot 100: 1525-1536.

Zhang XY, Loyce C, Meynard JM, Savary S. 2006. Characterization of multiple disease systems and cultivar susceptibilities for the analysis of yield losses in winter wheat. Crop Prot 25: 1013-1023.

Zheng B, Chenu K, Dreccer MF, Chapman SC. 2012. Breeding for the future: what are the potential impacts of future frost and heat events on sowing and flowering time requirements for Australian bread wheat (Triticum aestivum) varieties? Global Change Biol 18: 2899-2914.

Cite this article as: Gauffreteau A. 2018. Using ideotypes to support selection and recommendation of varieties. OCL 25(6): D602. 